\title{
SENTIDOS SOBRE GÊNERO E SORORIDADE A PARTIR DE NARRATIVAS DE MULHERES 'MULAS' DO TRÁFICO PRESAS EM UMA COLÔNIA PENAL DE PERNAMBUCO
}

\author{
DRUGS AND GENDER: A STUDY WITH 'FINE' WOMEN OF \\ TRAFFICKING IN A PERNAMBUCO FEMALE PENAL COLONY
}

\author{
Fernando da Silva Cardoso ${ }^{1}$ \\ Luísa Vanessa Carneiro da Costa ${ }^{2}$ \\ Vanessa Alexsandra de Melo Pedroso ${ }^{3}$
}

\begin{abstract}
RESUMO
A presente pesquisa tem como objetivo compreender como marcadores de gênero são operados no cotidiano de mulheres 'mulas' do tráfico, a partir de uma investigação realizada na Colônia Penal Feminina de Buíque, em Pernambuco. Trata-se de um estudo de caráter qualitativo, instrumentalizado a partir de entrevistas semiestruturadas. Os aspectos presentes nas narrativas das participantes da pesquisa demarcam as questões de gênero enquanto lentes por elas utilizadas na leitura de suas realidades individuais e coletivas. Marcadores de classe se sobressaem no modo como as entrevistadas enxergam-se entre si e nas relações de sororidade estabelecidas. Fatores ligados à categoria gênero são determinantes no modo pelo qual o sistema penal trata mulheres presas na Colônia estudada. Relações de sororidade, empoderamento mútuo e resiliência, protagonizadas pelas participantes da pesquisa, despontam enquanto notas à superação das opressões no tratamento penal direcionado a mulheres 'mulas' do tráfico.
\end{abstract}

Palavras-chaves: Drogas. Mulheres. Gênero. Pernambuco.

\footnotetext{
${ }^{1}$ Atualmente é Professor Adjunto I do Curso de Direito da Universidade de Pernambuco - Campus Arcoverde. Doutor em Direito - Pontifícia Universidade Católica do Rio de Janeiro, com período sanduíche no Centro de Estudos Sociais da Universidade de Coimbra, Portugal. Mestre em Direitos Humanos - Universidade Federal de Pernambuco. e-mail: cardosodh8@gmail.com

${ }^{2}$ Atualmente é Professora do Curso de Direito da Faculdade Sete de Setembro (FASETE). Mestra em Direito Universidade Católica de Pernambuco (UNICAP). Pós-graduada em Direitos Humanos: Educação e Ressocialização - Universidade Cândido Mendes (UCAM). Bacharela em Direito pelo Centro Universitário do Vale do Ipojuca (UNIFAVIP). e-mail: luisavanessa1@hotmail.com

${ }^{3}$ Atualmente é Professora de Direito Penal da Universidade Católica de Pernambuco (UNICAP). Pós-doutora pelo Programa de Pesquisa em Ciências sociais, Crianças e Adolescentes na América Latina da rede: PUC-São Paulo (BR) e Centro Latino Americano de Ciências Sociais (CLACSO). Doutora em Direito Penal pela Universidad Complutense de Madrid (España) e-mail: vanessampedroso@gmail.com
} 


\section{ABSTRACT}

The present research aims to understand how gender markers are operated in the daily life of women 'mules' of trafficking arrested in the Colony Feminine de Buique, in Pernambuco. This is a qualitative study, based on semi-structured interviews. The aspects present in the narratives of the participants of the research demarcate the gender issues as lenses used by them in the reading of their individual and collective realities. Class markers stand out in the manner in which the interviewees see each other and in established relations of sorority. Factors related to the gender category are determinants in the way in which the penal system treats women prisoners in the colony studied. Sorority relations, mutual empowerment and resilience, among the participants of the research, stand out as alternatives to overcoming oppression in the criminal treatment directed to women 'mules' of trafficking.

Keywords: Drugs. Women. Gender. Pernambuco.

\section{INTRODUÇÃO}

O presente trabalho apresenta parte dos resultados de um estudo mais amplo realizado durante o ano de 2016 na Colônia Penal Feminina de Buíque-PE pelas autoras e autor, o qual teve como lócus o estudo dos determinantes que perfazem o envolvimento de mulheres com o tráfico de drogas. Buscava-se, ainda, caracterizar e apresentar uma leitura sobre as repercussões da política antidrogas brasileira para a vida das mulheres, sob um enfoque dos estudos de gênero, tendo a referida Colônia enquanto locus.

Assim, neste estudo, são ressaltadas, tão-somente, as estratégias de sororidade (COSTA, 2004) protagonizadas por mulheres presas, umas com as outras, na busca pela ressignificação das violências vivenciadas no cárcere. Através da perspectiva de gênero (SCOTT, 1995; SAFFIOTI, 2004), procura-se entender as práticas de sociabilidade e de resistência feminina à violência presente na dinâmica e no cotidiano da estrutura carcerária, assim como os marcadores sociais que demarcam essa experiência, para além da responsabilização jurídica, e que subalternizam - duplamente - mulheres presas por tráfico de drogas, como sugerem Fonseca e Cardoso (2018).

Nesse sentido, a pesquisa é oriunda de questões como: Quais as intercessões entre tráfico e questões de gênero, a partir da prática da sororidade vivenciada por mulheres presas 


\section{Revista \\ Debates Insubmissos}

na Colônia Penal Feminina de Buíque-PE? Quais os sentidos e significados das estratégias de resistência protagonizadas por mulheres 'mulas'4 do tráfico em relação ao cárcere?

O objetivo geral do estudo consiste em compreender as intercessões entre tráfico e questões de gênero, frente às práticas de sororidade, vivenciadas por mulheres presas na Colônia Penal Feminina de Buíque-PE. Ainda, a presente pesquisa tem como objetivos específicos: discutir sobre a política antidrogas no Direito Brasileiro; relacionar o tráfico de drogas e as questões de gênero; e, por fim, analisar as intercessões entre tráfico e questões de gênero a partir de experiências de sororidade protagonizadas por mulheres presas na Colônia Penal Feminina de Buíque-PE.

Tem-se o interesse de analisar o duplo processo de vitimização de mulheres presas por tráfico frente às situações opressoras que lhes cercam na prisão, buscando refletir e questionar a construção patriarcal da guerra às drogas, tendo um olhar acerca das práticas de sororidade que atravessam tal contexto enquanto elementos à problematização do trinômio gênero/drogas/punição.

A reflexão sobre as intersecções entre drogas, tráfico e gênero, com base nas estratégias de sororidade de mulheres presas, pode possibilitar o aprofundamento de questões implícitas às injustiças que acompanham o tratamento penal ao tema e acerca de como a perspectiva de gênero pode ser importante ao aperfeiçoamento e ressignificação da política antidrogas. Afinal, os aspectos de vulnerabilidade feminina neste espaço, no qual o preconceito é potencializado devido ao quadro de estigmas sociais que mulheres 'mulas' carregam, oferece importantes lentes sobre como a Lei de Drogas tem contribuído com a administração da pobreza (feminina) e no reforço da exclusão com base no gênero, no Brasil.

Discutir sobre como mulheres presas por tráfico ressignificam, a partir de práticas de sororidade, as relações de poder e de opressão na prisão, incide na reflexão sobre a necessidade de consideração de desigualdades e indiferenças fincadas em questões de gênero como paradigmas basilares na/da responsabilização feminina.

\footnotetext{
4 'Mula' é um dos termos utilizados para definir uma pessoa que é coagida por traficantes para transportar drogas de forma ilegal, o qual será utilizado ao longo deste artigo.
} 
A presente pesquisa parte do pressuposto que existem poucos estudos que problematizam questões sociais relativas ao cotidiano de mulheres 'mulas' do tráfico e, especialmente, acerca dos aspectos de gênero que perfazem o seu cotidiano. $O$ olhar aqui construído sobre sociabilidades sororíficas entre mulheres presas no cenário da guerra às drogas representa um dos possíveis elementos a serem considerados por investigações ligadas aos grandes temas 'gênero' e 'drogas'.

Com base em tal perspectiva, espera-se que o estudo colabore para a discussão e visibilidade do referido contexto e sujeitas envolvidas, especialmente com a proposição de alguns insights de dimensão interdisciplinar e empírica sobre a condição de mulheres 'mulas' presas. Trata-se de um debate localizado - quanto aos sujeitos e universo estudado - e perspectivado - a partir da categoria gênero - enquanto estratégia à compreensão de questões invisibilizadas no grande debate sobre a guerra às drogas.

\section{A POLÍtica ANTIDrogas: QUESTÕes SOBRE O TRÁFICO NO DIREITO BRASILEIRO}

A análise de questões implícitas à política antidrogas, hoje, tem mobilizado inúmeras/os pesquisadoras/es. Especialmente, o debate sobre tráfico de entorpecentes e a posição ocupada pela mulher surge como forte aspecto, em decorrência das diversas problemáticas de gênero que perfazem esse campo. Direitos de mulheres presas, a perpetuação do patriarcado via guerra às drogas, a criminalização feminina da pobreza, entre outras questões diretamente ligadas à Lei 11.343/2006, tem sido, dentre outros problemas, objeto de investigação.

Nesse cenário, um aspecto central oriundo da política antidrogas, quanto às poucas perspectivas de solução na legislação brasileira, liga-se à premissa de que a política criminal de repressão às drogas insiste em tratar e reduzir as questões sociais por trás do uso e tráfico de entorpecentes a um problema estritamente jurídico-punitivo. O encarceramento em massa, a criminalização da pobreza, a reprodução do racismo via cárcere e a letalidade do sistema de segurança têm sido soluções visivelmente institucionalizadas no Brasil na dinâmica da guerra às drogas. 


\section{Revista \\ Debates Insubmissos}

A regulamentação da política de combate às drogas, até agosto do ano de 2006, estava definida nos termos das Leis $n^{\circ} .6 .368 / 76$ e $n^{\circ} .10 .409 / 02$. Esta segunda Lei objetivava dar um tratamento diferenciado aos temas disciplinados pela primeira, mas, os artigos vetados ${ }^{5}$ pelo então Presidente Fernando Henrique Cardoso fizeram dela letra morta, uma colcha de retalhos de difícil aplicação. Para sanar as divergências criadas com a promulgação da normativa acima mencionada, os Tribunais Superiores têm atuado no sentido de considera-las complementares, sendo a primeira de natureza material, descrevendo os tipos penais (crimes) e a segunda processual, criando regras para a forma de aplicação da Lei (SHECARIA, 2014; CARVALHO, 2014).

É fato que a Lei 11.343/06 não dispõe sobre mecanismos de implementação adequada para uma política de drogas, visto que é notória a aplicação de medidas retributivas, em detrimento de práticas restaurativas e/ou socioeducativas.

Gomes (2007) ao analisar a abrangência da Lei de Drogas em vigência, de uma forma geral, percebe que os tipos penais existentes na Lei 6.368/76 foram mantidos, sofrendo, todavia, uma majoração significativa da pena. Assim, mesmo prestigiando-se em normas caráter supralegal - a própria Constituição de 1988 - garantias ligadas a preservação da liberdade física das pessoas, fazendo do aprisionamento uma exceção, e lógica da guerra às drogas inverte essa premissa como assegura Cardoso (2019). Da análise superficial da Lei de Tóxicos nota-se que o legislador, em relação ao combate a prática do tráfico de entorpecentes, nos seus mais diversos modos, optou não só pelo endurecimento da pena a ela cominada, como também pela aplicação do regime mais severo em seu cumprimento.

A Lei de Tóxicos alcançou um maior punitivismo em relação às leis anteriores. Sua política criminal, é, notavelmente, ligada a mera aplicação da pena, composta de uma sistemática, traços e medidas expressivamente mais rígidas. Japiassu (2009, p. 25), sobre o cenário em questão, aponta que:

Os efeitos perversos da proibição da droga são potencializados nos países marcados pela desigualdade e pela exclusão social, como é o caso do Brasil e dos demais países em desenvolvimento, muito embora sejam também detectados nos países desenvolvidos.

\footnotetext{
5 Esses dispositivos tratavam de questões como: prevenção, tratamento, fiscalização, controle e repressão à produção de entorpecentes.
} 


\section{Revista \\ Debates Insubmissos}

Vale observar que com o advento da Política Criminal de Drogas, o enigma do uso indevido de entorpecentes, bem como o tráfico de drogas ilícitas, longe de ter sido solucionado, tem causado inúmeras injustiças e agravado problemas sociais.

Longe da premissa foucaultiana de que "as penas deveriam ser moderadas e proporcionais aos delitos, sendo, portanto, preciso punir de outro modo, eliminando a confrontação física entre soberano e condenado" (FOUCAULT, 2009, p. 71), a guerra às drogas tem significado o reforço do racismo e da criminalização da pobreza ${ }^{6}$.

No Brasil e no mundo vive-se uma avalanche legislativo-repressiva. Ao lado disso, o Estado tem negligenciado questões sociais de fundo que perfazem o cenário de guerra às drogas. Há, também, uma latente resistência por parte do Legislativo em reconhecer princípios, direitos e garantias concedidos à pessoa humana, os quais poderiam apresentar caminhos viáveis à Política Antidrogas, já que, pelo contrário, a tônica sobre o assunto tem sido mediada pelo proibicionismo e pela formalidade vazia e apolítica.

\subsection{Tráfico de drogas e questões de gênero: a Lei 11.343/06 e suas principais controvérsias}

Uma evidência no Brasil é: há a urgente necessidade de uma política mais eficaz no enfrentamento e prevenção às drogas, direcionada a cuidados e à redução de danos, fincada em princípios reformadores, educativos e sociopolíticos. Percebe-se a importância dessa premissa ao se assumir a perspectiva de que apenas uma política de drogas reformadora (CARVALHO, 2014), com olhar voltado para a inclusão social das pessoas e superação das desigualdades, é capaz de retirar indivíduos desse contexto e descontruir os danos históricos deixados - e ainda perpetuados - pela guerra às drogas.

No cenário brasileiro, a afirmação da política antidrogas está fincada no proibicionismo. A não diminuição do uso ou do comércio ilegal de drogas é, na verdade, resultado da miopia jurídico-política em lidar com as questões implícitas no agenciamento e reprodução desta prática em sociedade. A necessidade de uma política de drogas sabedora das necessidades

\footnotetext{
${ }^{6}$ Em suma, tem significado um potente instrumento na manutenção de desigualdades, injustiças sociais e, principalmente, com discursos acerca do endurecimento de leis e acirramento do punitivismo.
} 


\section{Revista \\ Debates Insubmissos}

básicas de usuários/as e/ou traficantes, de modo que todas/os possam ser alertadas/os dos efeitos que as drogas causam, é o elemento chave ao rompimento com a mera punição.

A Lei antidrogas, transporta, especialmente, uma questão chave: não apresenta nenhum instrumento que possa evidenciar estratégias inclusivas, do ponto de vista social, em relação a aquele/a que comete o ato ilícito (se homem e/ou mulher), e, portanto, termina por aplicar a mesma cominação de pena para ambos os sexos biológicos ou gêneros, desconsiderando elementos sociais e de gênero importantes nesses casos.

De forma que, com uma política de enfrentamento a entorpecentes inteiramente proibicionista, e, por vezes, contraditória, o consumo e o tráfico tendem a aumentar cada vez mais, e a guerra às drogas não tem colaborado para sua diminuição, contribuindo tão somente para a ampliação do mercado ilegal, cada vez mais lucrativo, vez que se expande também o crime organizado.

O Departamento Penitenciário Nacional (DEPEN) (2014), ligado ao Ministério da Justiça, em estudo, constatou que a maioria das mulheres presas pela criminalização de drogas ocupa uma posição de coadjuvante nessa modalidade de crime. Realiza serviços de transporte de drogas em pequeno comércio, tão-somente, na maioria das vezes por serem também usuárias, sendo ínfimo o exercício de atividades de gerência do tráfico por elas.

Ainda conforme dados do DEPEN, o ritmo de crescimento da taxa de mulheres presas na população brasileira merece extrema atenção: “De 2005 a 2014 essa taxa cresceu numa média de 10,7\% ao ano. Em termos absolutos, a população feminina saltou de 12.925 presas em 2005 para 33.793 em 2014” (2014, p. 39).

O trajeto de enfrentamento às drogas é marcado pela aplicabilidade reducionista da norma penal, demarcando um complexo e amplo cenário de incongruências e injustiças a partir do aparato controvertido no/do direito. Pensar, por exemplo, que grande parte das mulheres que estão presas representam as rendas de suas próprias famílias, são as chefes de suas casas, tornase uma reflexão forçada acerca de como o aprisionamento em massa ainda trará grandes e graves problemas a sociedade brasileira. Políticas de enfrentamento às drogas necessitam, em 


\section{nevitate

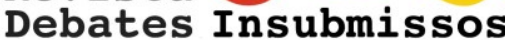

se tratando do cotidiano de mulheres, dimensionar questões de gênero implícitas desde o agenciamento ao tráfico até a responsabilização.

Os altos índices de aprisionamento de mulheres, sejam elas usuárias ou traficantes, desenha, nos dias de hoje, uma nova dinâmica penal-punitiva: sobre a incapacidade de se relacionar questões sociais e de gênero na responsabilização feminina. Estado e sociedade têm caminhado lado a lado na construção perversa de um amplo grau de invisibilidade e injustiça direcionados a esse grupo.

Afinal, mulheres têm ocupado o lugar de mão de obra barata e facilmente substituível nas redes do crime e do tráfico (COSTA, 2016; 2018), são apresentadas como cultivadoras, coletoras, vendedoras de varejo, correios humanos, espaços nos quais são conhecidas, geralmente, como 'mulas', dentre outras nomenclaturas, especialmente como imagem sinônima à introdução de drogas em prisões.

O Estado, por outro lado, não tem oferecido centros próprios e adequados para atender às necessidades femininas; a falta de atenção aos problemas de saúde física ou psíquica das detentas, e, até mesmo, sobre as filhas e filhos destas, que, na grande maioria das vezes, ficam abandonados por não terem uma base familiar, segue demarcando o punitivismo contemporâneo. Ao lado destas questões, oportunidades educativas, de saúde básica ou medidas que possam trazer oportunidades para o reingresso na sociedade, esbarram na utopia de uma sociedade receptiva a pessoas que estiveram presas.

Marcadas por agressões e discriminações cotidianas, mulheres também têm se tornado objeto de expiação penal, têm sido, frequentemente, vítimas de violências de gênero por parte do Estado e daqueles que fazem o sistema prisional.

Em paralelo a crimes cometidos por homens, mulheres 'mulas' praticam atos bem menos lesivos e são culpabilizadas para além do determinado em lei, tornam-se um perigo a fé pública, aos bons costumes. A superlotação ${ }^{7}$ nas prisões também é resultado do patriarcalismo que permeia a Lei.

\footnotetext{
${ }^{7}$ Esse argumento soma-se à expansão do Estado penal, do racismo e da seletividade dos órgãos de Segurança Pública e do Poder Judiciário (BOITEUX, 2014) na explicação deste problema social.
} 
Tocadas por uma sociedade extremamente sexista, traçada por padrões patriarcais, subalternizadores e machistas, a estrutura de poder é desigual frente a mulheres e homens que cometem crimes, questões de gênero seguem deixando um saldo negativo às mulheres 'mulas', por exemplo.

\section{QUESTÕES GÊNERO? NOTAS A PARTIR DE NARRATIVAS DE MULHERES 'MULAS' DO TRÁFICO PRESAS EM UMA COLÔNIA PENAL FEMININA DE PERNAMBUCO}

A metodologia utilizada nesta pesquisa desenvolve-se a partir da modalidade estudo de caso, com abordagem qualitativa. Os tipos de pesquisa utilizados foram: a bibliográfica, descritiva e exploratória. Partiu-se, quanto a coleta de dados, de uma de observação não participante, que fez uso de diário de campo, assim como de entrevista semiestruturada, tendo sido as informações lidas à luz da análise de conteúdo.

O estudo foi realizado na Colônia Penal Feminina de Buíque, situada na Rua D. Amélia Cavalcanti, s/n, na cidade de Buíque-PE. A entrevista foi realizada com nove mulheres encarceradas ${ }^{8}$. Elegeu-se como público da pesquisa mulheres que estivessem presas por tráfico de entorpecentes, e que concordaram em responder as questões formuladas e mediante assinatura do TCLE, para que, a partir da narrativa da história de vida de cada uma, fosse possível refletir sobre as intersecções entre a condição de mulheres 'mulas' do tráfico e a política antidrogas.

Trataremos, pois, de questões relacionadas a práticas de sororidade entre mulheres encarceradas nesta Colônia Penal, de forma a analisar como essa categoria perfaz a condição de presa e sobre como a instituição total articula novas formas de opressão marcadas por questões de gênero. Também, sobre como as experiências vividas na penitenciária ressignificam os laços de gênero e sociabilidade nesse espaço.

\footnotetext{
${ }^{8} \mathrm{O}$ presente estudo foi submetido através da Plataforma Brasil e devidamente aprovado pelo Comitê do Centro Universitário do Vale do Ipojuca, conforme Parecer Final nº 1.694.180.
} 


\section{Revista \\ Debates Insubmissos}

A análise das narrativas permite, em um primeiro momento, relacionar as intersecções entre um suposto ensaio à vontade de autonomia feminina e o dilema do não reconhecimento de um lugar social vivido pelas entrevistadas. Em suma, os achados dialogam com representações experimentadas pelas mulheres presas quanto ao não exercício de sua cidadania.

Esse obstáculo é representado pela impossibilidade ou inexistência de empregos dignos que marca as vivências das entrevistadas, aspecto base, segundo elas, a não vivência de outros direitos. Marcadas pela carência e precariedade das oportunidades de trabalho, a subjetividade das mulheres investigadas, como se vê no excerto a seguir, relaciona, antes e depois da vivência do cárcere, a sua condição humana como sendo mediada pela subsistência financeira decorrente do trabalho exercido:

Eu já trabalhei em lar e em restaurante, eu era cozinheira e garçonete, mas não tinha a carteira assinada e só recebia $\mathrm{R} \$ 100,00$ por semana, achava pouco para cuidar de três crianças e ainda mais para pagar aluguel, energia, água, não tinha como dar nada de melhor para meus filhos... (Entrevistada $\mathrm{n}^{\mathbf{0}} 09$ ).

A fala acima mencionada traz à mente o cotidiano de vulnerabilidade social vivido por mulheres, sejam elas inseridas em alguma situação de crime ou não. Em suma, a precariedade da vida feminina cotidiana é um elemento que merece ponderação quando se trata do agenciamento de mulheres traficantes, mas não apenas para elas (COSTA, 2016; 2018; COSTA; CARDOSO, 2017).

As falas marcam o senso de que a condição de presas reforça, dupla e negativamente, esse quadro:

Se eu sair daqui amanhã eu não sei se arrumaria um emprego, porque eu serei expresidiária e também porque ninguém quer ajuda ninguém; só julgam; por outro lado, só quem pode julgar é Deus. Por isso, se na rua alguém me perguntar se sou expresidiária vou dizer: sou ex-presidiária, mas venci e estou aqui para concertar meu erro (Entrevistada $\left.n^{\circ} 09\right)$.

O desejo de autonomia é mediado ora pela produção de estigmas advindos do cárcere, ora pelo sexismo e patriarcado experimentados antes da entrada na prisão (COSTA; CARDOSO, 2017). O empenho para obterem autonomia e lugar social é sempre interpelado pelo imaginário permanente de negação sistemática de suas cidadanias baseada em questões de gênero: Antes de vir presa eu tomava conta dos meus filhos, lavava, passava, arrumava minha 
casa, levava as crianças na escola; mas já fazia um ano que eu estava desempregada (Entrevistada $\left.\mathrm{n}^{\circ} 09\right)$.

As subjetividades produzidas pelas entrevistadas são mediadas a partir de marcadores de subcidadania, que acrescem a condição de mulheres 'mulas' do tráfico dimensões de classe e gênero (COSTA, 2016). Esse dado, segundo Miguel e Biroli (2014), é reforçado pelo fato de que mulheres são expostas à vulnerabilidade cotidiana com base na premissa de que suas expectativas pessoais (socialmente construídas e reforçadas) necessitam se adequar aos padrões de gênero hegemônicos, o que é determinante na existência de novas e sistemáticas violências ${ }^{9}$.

Entretanto, é na resiliência (COSTA; CARDOSO, 2017) e nas decisões de luta protagonizadas (FONSECA; CARDOSO, 2018) pelas entrevistas que se vê alternativas a esse quadro. Em suma, há, nas narrativas analisadas, uma recorrente percepção individual sobre a necessidade de se auto-empoderarem, que é representada, recorrentemente, pelo desejo de deixar a prisão: "Me sinto preparada para voltar para a rua, é tudo que eu mais quero na vida (Entrevistada $\left.\mathrm{n}^{\circ} 06\right)^{\prime}$.

Observa-se, portanto, que a marginalização da mulher, retratada na desvalorização social e cotidiana a qual estão submetidas, é, também, presente na visível diferenciação que as entrevistadas demonstram ao falar sobre si mesmas e, principalmente, ao buscarem agir frente a tal quadro de opressões, marcado por assimetrias de gênero. Este é, sem dúvidas, um importante marcador à compreensão de como as desigualdades de gênero vividas em sociedade atuam e alimentam a violência institucionalizada no contexto prisional.

Fragilidades emocionais - marcadas por falas pausadas e voz cortada - perfazem as narrativas de mulheres presas por tráfico (COSTA, 2016). Em suma, lembranças de responsabilidade maternas e/ou ligadas a sentimentos afetivos demarcam as subjetividades das entrevistadas e reforçam o auto estigma (GONZAGA; CARDOSO, 2018), como se vê no excerto a seguir: "Eu ajudava minha família nas despesas de casa, comecei a trabalhar aos 14

\footnotetext{
${ }^{9}$ As reflexões propostas por Costa, Cardoso e Cavalcanti (2016) em 'Violações de Direitos Humanos no Brasil: notas a partir do $5^{\circ}$ Relatório Nacional de Direitos Humanos' contribuem para pensar as diversas questões que tangenciam este e outros cenários, quando se trata do contexto brasileiro.
} 


\section{Revista \\ Debates Insubmissos}

anos de idade, antes de ser presa ganhava $\mathrm{R} \$ 600,00$, mas quase não estava dando para comprar os remédios da minha mãe" (Entrevistada $n^{\circ} 03$ ).

A condição de inferioridade presente nos diálogos das mulheres entrevistadas perfaz, por outro lado, a imagem acerca do não reconhecimento de suas profissionalidades ${ }^{10}$. O trabalho precário e/ou a ausência de garantias de direitos, associados à negligência de figuradas paternas em relação às suas famílias, marcam a trajetória de vida das participantes da pesquisa até o agenciamento pelo tráfico de drogas: "Eu era agricultora, e as despesas de casa eram divididas entre minha mãe e eu, hoje ela está se virando sozinha, não sei como ela está fazendo, só Deus (Entrevistada n $\left.{ }^{\circ} 04\right)^{\prime \prime}$.

Ao que constata, a grande maioria das mulheres, senão todas, eram chefes de suas famílias. Trabalhavam para manter seus filhos e até outros membros da família (irmãs, mães, irmãos e, até mesmo, sobrinhos/as e cunhadas. A vulnerabilidade social a qual sempre estiveram submetidas mediou, ao passo que reafirmava, os marcadores de gênero inerentes ao perfil de 'mulas' (BOITEUX, 2014; GONZAGA; CARDOSO, 2018). Como matriarcas familiares, carregam o peso da culpa pelo abandono afetivo de seus familiares, como se os deixassem, com isso, à própria sorte.

Eu me sinto uma mãe não exemplar, não foi o exemplo que dei para eles e o que eu sinto é que nunca imaginei essa vida de presa... uma vida de todo dia a mesma coisa, todo dia as mesmas pessoas, não ando como andava na rua, não posso procurar um trabalho, não tenho contato com a família (Entrevistada $n^{\circ} 09$ ).

Ou, ainda: "Me sinto muito revoltada porque eu não posso cobrar nada de ninguém, quem errou foi eu, eu me revolto comigo mesmo (Entrevistada $n^{0}$ 09)". As mulheres entrevistadas apresentarem em suas narrativas novos olhares a respeito dos desafios à igualdade de gênero e à desconstrução de estigmas em torno de suas condições de presidiárias. Lidam em suas falas com o processo de subalternização em relação ao discurso arcaico, patriarcal e sexista que media o estigma da punição. Dialogando com esse achado, Saffioti (2004) aponta que

\footnotetext{
${ }^{10}$ Uma vez terminada a pena e postas em liberdade, seus antecedentes penais prejudicam a possibilidade de encontrarem emprego formal decente, o que perpetua o círculo vicioso de exclusão social e encarceramento no qual estão inseridas (WOLA, 2016, p. 10).
} 
Revista

Debates Insubmissos

mulheres foram treinadas para se sentirem culpadas, ainda que elas tenham razão, pois sempre estão em condição de inferioridade em relação aos homens.

Sobre este aspecto, vejamos:

Quando sai daqui a mulher é muito descriminada, muito mais do que um homem ex presidiário, a mulher não arruma trabalho e voltam para o mundo do crime novamente, tem uma menina que conheci aqui que ela saiu e foi muito discriminada, não arrumou trabalho, sei que lá fora ela tava era passando fome, foi e voltou para aqui 5 vezes, Deus me defenda de cair numa tentação dessa (Entrevistada nº 09).

Por outro lado, a pesquisa evidencia práticas de empoderamento e sororidade que são basilares na existência e na constituição das subjetividades (COSTA, 2004) também para as entrevistadas. Por exemplo, a entrevistada $n^{\circ} 04$, que apesar da dificuldade vivenciada na prisão, afirma resistir ao preconceito, ao machismo e ao patriarcalismo a partir dos laços afetivo-sociais firmados com outras mulheres presas: "Normal, ser uma mulher presa... não sei explicar, mas tem que ter muita fé, aqui estamos todas juntas, longe de casa, da família... há umas brigas, mas todas sofrem igual, umas há mais tempo do que outras e por aí vai... aqui é uma tristeza (Entrevistada $\mathrm{n}^{\circ}$ 04).

As mulheres entrevistadas evidenciam em suas narrativas a necessidade de resistirem às opressões fundadas em questões de gênero na prisão. Ao complementar sua fala, a Entrevistada $\mathrm{n}^{\mathrm{o}} 04$ realça a resiliência exercida no enfrentamento a práticas sexistas e discriminatórias no aprisionamento, ao passo que destaca os desafios de, após a liberdade, conseguir superar estigmas cotidianos, vejamos:

A vontade de sair daqui é tão grande que acho que estou preparada, quero mudar de vida, arrumar um emprego, vender roupa, trabalhar para mim mesmo, eu não sabia costurar e aqui eu aprendi, aprendi a fazer ponto cruz... aqui é uma escola, você aprende a mudar para melhor... porque para pior você sabe que vai viver no castigo, isolamento e para melhor você ainda tem um esperança de sair... Estudei até a $5^{\circ}$ série (não estudo aqui, não tá tendo aula no momento, por falta de professor, mas tá para começar já) (Entrevistada $\left.n^{\circ} 04\right)$.

As entrevistadas aduzem em suas narrativas pela vontade implícita de serem livres e de terem cidadania. Conforme Costa (2018), o processo perfaz a noção de que as questões de gênero também atuam como elemento de resistência política frente à discriminação e ao estigma vividos. 


\section{Revista \\ Debates Insubmissos}

A partilha do sentimento de sororidade na prisão, para as entrevistadas, significa na desconstrução de processos de violência para além da própria prisão. Traduzem uma dimensão coletiva do empoderamento feminino para a superação do mero punitivismo penal. No excerto a seguir, a Entrevistada n ${ }^{\text {a }} 05$ articula argumentos vividos no seu trajeto de luta cotidiana contra a estrutura de opressão agenciada por meio do encarceramento:

E tenho ensino médio, curso de informática, tive minha filha e mesmo assim eu ia para a aula, levava ela pra aula comigo e tudo, mas quando a pessoa vem se formar, arrumar uma bolsa de estudos... demora. É tanto que aqui dentro eu pedi para estudar tudo de novo, quero relembrar tudo o que vi na escola, quero conseguir minha remissão e sair daqui.

Pode-se observar que, para as entrevistadas, o processo de ressocialização no qual se inserem reside na busca em não desistir de lutar por seus direitos. Na verdade, se trata de uma resistência partilhada, como sugere Costa (2004), construída a partir dos laços de sororidade que as unem. Como relata a Entrevistada $n^{0}$ 01, muito emocionada, chorando e inquieta, a punição feminina sempre é mediada por sua condição de feminilidade, marcada por questões de gênero, anteriores a sua prisão:

Aqui dentro eu penso muito na minha mãe, minhas filhas, tô perdendo de acompanhar a juventude delas. Em momento algum eu chorei, mas quando esse portão abriu, a ficha caiu, imaginei como minha mãe ia se sentir; para entrar é fácil, mas para sair daqui é difícil, nem tão cedo sai.

A fala da Entrevistada acima demonstra, assim como se vê nas entrevistas das outras participantes da pesquisa, demarcam um forte imaginário de exclusão. Relata como se sente em não ver as filhas, lamentando-se por não se fazer presente no crescimento e educação das crianças. É a partir desses contornos - individuais e coletivos - que a opressão opera na vida de mulheres presas por tráfico, suas relações de pertencimento social são, sempre, resultantes de quadros de abandono e de marginalidade

Ao que nos aparece, as práticas de sororidade protagonizadas por mulheres presas significam na resposta automática em se superar o sentimento de exclusão - ou solidão gestado na prisão. Certamente, as respostas deveriam decorrer da minimização do direito penal como recurso ao enfrentamento da participação feminina no tráfico de drogas, logo a partir da ampliação de alternativas penais que evitem os impactos gerados pelo encarceramento 
feminino. A fala da Entrevistada n 07, chama atenção para o cenário: “Aqui dentro eu só recebo visita do meu pai, se eu só tenho ele, só tenho um irmão, mas tá preso, o outro morreu; sinto falta de uma mulher para me visitar e conversar coisas da minha vida, desabafar, as vezes converso com meu pai, mas não é a mesma coisa".

Em meio a pausas, chorando, foi colhida a fala da entrevistada acima. A realidade encontrada na Colônia Penal Feminina de Buíque, em Pernambuco, perfaz, na verdade, mais um quadro de negação de um projeto alternativo ${ }^{11}$ à responsabilização feminina por tráfico de entorpecentes, mais uma faceta da guerra às drogas contemporânea. As práticas de sororidade traduzem a resiliência de mulheres presas à inospitalidade da prisão e ao estigma que dela deriva (COSTA, 2016; 2018).

Observa-se que o isolamento é a tônica da existência das entrevistadas. Os códigos e regras rígidas que mediam as relações entre as mulheres participantes da pesquisa e os profissionais da Colônia cartografada são desenhados pelas expressões e metáforas do fundamento violento que perfaz a prisão enquanto instituição total.

Nunca falei nada e até hoje não falo sobre minha vida, porque você é a primeira pessoa que me perguntar como me sinto, você é a primeira pessoa que eu tô desabafando; o caminho que eu pisei foi errado, meus pais não sentam para conversar comigo, eles criam, mas não conversam, não dão atenção (Entrevistada n $\left.{ }^{\circ} 05\right)$.

$\mathrm{O}$ excerto acima demarca uma das falas mais emotivas em meio às entrevistas. Pausas como: “está se sentindo bem?” ou, “sente-se à vontade para continuarmos?”, “quer uma água?”, foram intervenções constantes. E narra a Entrevistada 05:

A falta que eu sinto não é de bem material, que é hoje e não é amanhã, se eu tivesse mais atenção, mais diálogo do meu pai, muita coisa teria sido evitada, tô aqui há 2 anos e 2 meses e meu pai sequer me mandou uma carta e nem vem me ver, eu não tô aqui porque eu quis.

Segundo Costa (2016), mulheres são duplamente vitimadas, física e psicologicamente, pela dominação e discriminação de gênero que permeia a prisão. O Estado, em meio ao sexista e caótico sistema carcerário atual, não tem refletido sobre as inadequações e injustiças perpetuadas no processo de responsabilização de mulheres, especialmente quando se trata de

\footnotetext{
${ }^{11}$ Trata-se de implementar programas específicos para oferecer alternativas a mulheres que por suas condições de vulnerabilidade e contexto em que vivem foram atraídas pela criminalidade organizada (WOLA, 2016).
} 


\section{Revista \\ Debates Insubmissos}

suas prisões em decorrência do agenciamento pelo tráfico de drogas. Assim, as relações de sororidade protagonizadas entre as entrevistadas representam, por um lado, a resistência à opressão estatal, e, por outro, o protagonismo feminino frente ao patriarcado que está implícito na dinâmica prisional.

A reafirmação da díade punição/patriarcado, problematizada anteriormente, também é presente na constatação de que até mesmo espaços de acompanhamento psicológico fornecidos pela Colônia universo da pesquisa não possibilitam a (re)construção das subjetividades das mulheres entrevistadas. Há, inclusive nos espaços de diálogo, o reforço de marcadores de gênero enquanto articuladores de pena, vejamos: "Quando estou perturbada, peço para ser acompanhada pela psicóloga, quando estou com vontade de chorar, para não chorar na cela, eu procuro, mas ainda me sinto constrangida, porque ela diz: olha vão chorar depois que faz o errado" (Entrevistada $\left.\mathrm{n}^{\mathrm{o}} 05\right)$.

A violência exercida através de símbolos ligados à feminilidade (CARNEIRO, 2002; RAMOS, 2012) é realçada na vida carcerária das entrevistadas. Como também narra a Entrevistada $n^{\circ}$ 07: "Fui no ginecologista, um homem e eu me senti muito envergonhada, porque aqui é um lugar só de mulher, mas queria que fosse uma mulher porque ela tem a mesma coisa que a pessoa tem" (Entrevistada $\left.n^{\circ} 07\right)$.

Notamos que diversas vulnerabilidades de gênero são presentes na vida das mulheres, como se percebe no excerto a seguir:

\footnotetext{
Se fosse uma médica eu me sentiria melhor, mais a vontade, feito o exame de lâmina quando disseram que era um homem, fiquei logo com medo, se fosse um homem que só fizesse o seu trabalho, mas não - mesmo sendo homem a pessoa tem que ir, porque se não for, tem que assinar um termo (Entrevistada $\left.n^{\circ} 05\right)$.
}

Se sentindo desconfortáveis em relação ao ambiente masculinizado em que vivem, rodeadas de práticas que as masculinizam, buscam, como na narrativa acima, a liberdade de serem reconhecidas diante da norma penal, notadamente, patriarcal, machista, sexista e autoritária.

É preciso considerar que outras (potenciais) vulnerabilidades comuns às mulheres (marcadores de classe, raça, etnia, escolaridade e etc.), são intermediados no discurso de 
Revista

Debates Insubmissos

responsabilização penal e, também, as acompanham antes mesmo da entrada na prisão. A cadeia, nesse sentido, tão-somente reafirma marcas patriarcais cotidianas, absorvidas inclusive em relação aos papéis de gênero no contexto do tráfico de drogas.

\begin{abstract}
Já sofri muita violência psicológica quando transportava a droga porque precisava está com a mercadoria certa, no horário certo e no lugar, se eu atrasasse me ligavam cobrando e eu ficava com medo... dos donos, de que fizessem algo com minha família... você quer sair e não consegue mais, porque se envolve com muitas pessoas, corre até risco de morte, porque eles querem garantia de que ninguém vai abrir a boca, e não confiam em ninguém (Entrevistada $\mathrm{n}^{\circ} 04$ ).
\end{abstract}

Nesta perspectiva é possível identificar que a estrutura social na qual as entrevistadas se inserem é marcada pela interseccionalidade de opressões (CRENSHAW, 2002; CHERNICHARO, 2014), mediadas pela subordinação de gênero. A prisão opera enquanto contexto afirmador de uma condição na qual as mulheres entrevistadas são marcadas pelo medo de si, supostas vítimas de suas próprias fragilidades sociais. Assim, nas narrativas analisadas, tomam seus espaços sociais como sendo restritos a direitos mínimos. Certamente, tal imaginário é resultado das relações de preconceito firmadas na prisão e fora dela, nas quais as categorias mulher e presidiária se interseccionam por meio do patriarcado.

Não me sinto preparada para voltar a conviver em sociedade porque eu não sei como será lá fora, aqui já é uma rotina e eu tenho medo até de sair, ou você pratica o mesmo só para não morrer de fome ou.... Antes era totalmente diferente, ninguém me tratava com aquele preconceito e hoje eu sei que quando sair daqui vai ser muito difícil por questão de emprego, as meninas que saem daqui dizem o quanto é difícil. É por isso que muitas praticam o crime novamente, para voltar pra cá e ter o que comer; muitas não passam uma semana, 15 dias lá fora e voltam (Entrevistada $\mathrm{n}^{\circ} 05$ ).

$\mathrm{O}$ isolamento que cinge as experiências das mulheres entrevistadas alude à imagem sobre como o Estado tem tomado o encarceramento como tônica do enfrentamento ao tráfíco de drogas. O diálogo travado nesta investigação, inclusive, assume uma representação distinta da que, em tese, os demais agentes de segurança significam às participantes da pesquisa, como se vê:

Todo mundo erra, mas tenho fé em Deus que isso não vai mais acontecer não. Me arrependo muito do que fiz... foi a primeira vez que fiz isso né? Me sinto muito ruim, uma mulher aqui dentro, sei lá... foi muito bom conversar com você, obrigada por tudo. A pessoa desparece sabe, fica mais leve, mais maneira; primeiramente a ajuda de Deus e segundo a sua, é bom conversar com alguém que não trate mal (Entrevistada $\left.n^{\circ} 02\right)$. 


\section{Revista \\ Debates Insubmissos}

A relação entre a participante e o/a pesquisador/a dimensiona como a metáfora do acolhimento é determinante nos processos de ruptura por elas protagonizados na prisão. Narrativas marcadas por emoções, como no excerto acima, indicam que as expressões de individualidade podem ser ressaltadas quando se possibilita a mulheres em situação de cárcere romperem com estereótipos e assumirem seus lugares de fala. Esse achado da pesquisa dialoga com o fato de que as mulheres entrevistadas enxergam estratégias de sororidade como formas de, coletivamente, construírem espaços de resiliência à violência da prisão.

[...] nunca me esqueço da mulher que morreu aqui, tenho fé em Deus de nunca mais ir em uma cadeia, aqui é a cadeia do não... não pode nada, porque tá presa e não em casa. A última ligação que fiz aqui, faz dois anos, ninguém entrega meu catatau (são as cartinhas, os bilhetinhos que elas fazem para o chefe de segurança entregar aos familiares delas quando querem se comunicar) (Entrevistada $\mathrm{n}^{\mathrm{o}} 05$ ).

As experiências de mulheres mulas do tráfico, seja em relação às vivências dentro e/ou fora do cárcere, convivem com práticas opressoras de gênero, por um lado, e em relação à busca por liberdade, por outro. Encontram na reciprocidade umas com as outras, alternativas ao patriarcado (FONSECA; CARDOSO, 2018) presente na prisão e fora dela.

\section{CONCLUSÕES}

A partir das narrativas das mulheres 'mulas' do tráfico de drogas, reflete-se como o sistema penal opera em relação à consideração (ou não) de diversas questões de gênero com as quais as detentas convivem. Ainda, é observado que as mulheres participantes desta pesquisa se enxergam em suas posições de gênero, buscam desconstruir a desigualdade de gênero vivida de maneira intuitiva e ensaiam uma ressignificação da inospitalidade do cárcere a partir de aspectos de sororidade e de empoderamento.

Em relação ao preconceito contra a mulher, dentro e fora da prisão, notam-se as dificuldades pelas quais as detentas passam, mesmo estando em sociedade. É possível apreender que a vulnerabilidade e desigualdade social por elas demarcam diferentes processos de exclusão e o agenciamento para o tráfico de drogas. Entretanto, no contexto do crime, os marcadores de gênero tendem a prevalecer e estabelecer os papéis exercidos por mulheres e homens. 


\section{Revista \\ Debates Insubmissos}

A compreensão dos marcadores de gênero é, assim, de suma importância na compreensão do lugar ocupado pelas entrevistadas. Afinal, só a partir de tal leitura é construída uma explicação que considere as desigualdades persistentes entre mulheres e homens, inclusive quanto às condições de mulheres 'mulas' do tráfico, no momento de aplicação das leis penais.

Em uma sociedade intensamente hierárquica, traçada por padrões de subalternidade decorrentes de questões de gênero, mulheres 'mulas' são, na prisão e fora dela, vítimas de inúmeras e incessantes violências. Vê-se o quão amplo e histórico é o machismo instaurado no cárcere, a partir das leis e na sociedade, que repercute implícita e fortemente nos 'padrões de gênero' também assumidos no/pelo sistema penal no contexto da guerra às drogas. As mulheres entrevistadas lutam e resistem contra a opressão de gênero que é disfarçada no punitivismo. A sororidade não é uma metáfora utópica da possível união vazia entre as mulheres, representa, outrossim, a resiliência frente à estrutura autoritária na qual o cárcere as insere.

A violência de gênero caminha lado a lado com a história de vida das presas; está sempre conectada ao sexismo e ao patriarcado das relações construídas no espaço prisional estudado, tendo em vista a grandeza que tal fator toma nas dinâmicas de preconceito e de discriminação por elas narradas, engendradas na estrutura patriarcal e proibicionista sob a qual opera a prisão e seus agentes.

No ambiente carcerário, a violência sofrida pelas mulheres participantes da pesquisa aparece, diariamente, sob a forma de múltiplas e multifacetadas violências, estas que, além de estarem explícitas fisicamente, constroem as suas subjetividade e sentimentos.

A dinâmica da "guerra às drogas" tem punido, de modo mais incisivo, as mulheres (sobretudo as negras e pobres) pelos mesmos crimes que também são cometidos por homens, mas que assumem dimensões concretas bastante distintas. No entanto, o Poder Judiciário, em sua feição machista e de baluarte da guerra às drogas, apesar de reforçar o sexismo punitivista que, como visto no universo da pesquisa, é evidente, também tem se deparado processos de resistência e de sororidade, que mesmo não sendo idealizados a partir de tais premissas, são feministas e antiproibicionistas. 
Assim, prefere-se pensar o cenário a partir das relações de sororidade, empoderamento mútuo e resiliência feminina, como nas práticas protagonizadas entre as mulheres entrevistadas nesta pesquisa, enquanto notas de resistência à opressão estatal e para a superação das opressões no tratamento penal de mulheres 'mulas' do tráfico na prisão.

\section{REFERÊNCIAS}

BOITEUX, Luciana. Drogas e Cárcere: repressão às drogas, aumento da população penitenciária brasileira e alternativas. In: SHECAIRA, Sérgio Salomão (Org.). Drogas: uma nova perspectiva. São Paulo: IBCCrim, 2014.

BRASIL. Departamento Penitenciário Nacional. Levantamento Nacional de informações penitenciárias INFOPEN mulheres: junho de 2014. Ministério da Justiça, Brasília- DF, 2014. $42 \mathrm{p}$.

CARDOSO, Fernando da Silva (org.). Encarceramento e guerra às drogas: leituras críticas sobre o estado penal contemporâneo. 1. ed. v. 1. Rio de Janeiro: Gramma, 2019.

CARNEIRO, Henrique. As necessidades humanas e o proibicionismo das drogas no século XX. Revista Outubro, São Paulo, v. 6, p.115-128, 2002. Disponível em: http://outubrorevista.com.br/as-necessidades-humanas-e-o-proibicionismo-das-drogas-noseculo-xx/. Acesso em: 17 nov. 2019.

CARvalho, Salo de. A política criminal de drogas no Brasil: estudo criminológico e dogmático da Lei 11.343/06. São Paulo: Saraiva, 2014.

CHERNICHARO, Luciana Peluzio. Sobre mulheres e prisões: seletividade de gênero e crime de tráfico de drogas no Brasil. 2014. 160 f. Dissertação (Mestrado em Direito), Universidade Federal do Rio de Janeiro, Programa de Pós-graduação em Direito da Faculdade de Direito da Universidade Federal do Rio de Janeiro, 2014.

COSTA, Gustavo Gomes da; CARDOSO, Fernando da Silva; Cavalcanti, Gabriela Guimarães. Violações de Direitos Humanos no Brasil: notas a partir do $5^{\circ}$ Relatório Nacional de Direitos 
Humanos. Prisma Jurídico, v. 14, n. 2, p. 195-127, 2016. Disponível em: https://periodicos.uninove.br/index.php?journal=prisma\&page=article\&op=view\&path $\% 5 \mathrm{~B} \%$ 5D=4935\&path\%5B\%5D=3092. Acesso em: 15 nov. 2019. DOI: https://doi.org/10.5585/prismaj.v14n2.4935.

COSTA, Luísa Vanessa Carneiro. Amor Bandido? Questões sobre a condição de mulheres “mulas" do tráfico sob uma perspectiva de gênero. 2016. 113 f. Monografia (Bacharelado em Direito), Centro Universitário do Vale do Ipojuca, 2016.

COSTA, Luísa Vanessa Carneiro; CARDOSO, Fernando da Silva. 'Só fui buscar a droga': intersecções entre gênero e tráfico de drogas - sobre a posição social de mulheres mulas. Anais... II Congresso Pernambucano de Ciências Jurídicas - Universidade de Pernambuco, vol. 2, ISSN 2526-5938, 2017, Arcoverde, 2017. Disponível em: https://drive.google.com/file/d/13F_CQL_N195VbW-_0bAxy_WS9eJ9NI-7/view. Acesso em: 14 nov. 2019.

COSTA, Luísa Vanessa Carneiro. Tráfico de drogas e questões de gênero: relendo a lei 11.343/2006. In: CARDOSO, Fernando da Silva. Direitos humanos: reflexões a partir da arte, gênero(s) e movimentos sociais. 1. ed. v. 1. Maringá: Viseu, 2018.

COSTA, Suely Gomes. Movimentos feministas, feminismos. Rev. Estud. Fem., Florianópolis, v. 12, n. spe, p. 23-36, dez., 2004. Disponível em: http://www.scielo.br/scielo.php ?script=sci arttext\&pid=S0104-026X2004000300003\&lng=en\&nrm=iso. Acesso em: 16 nov. 2019. DOI: http://dx.doi.org/10.1590/S0104-026X2004000300003.

CRENSHAW, Kimberlé. Documento para o encontro de especialistas em aspectos da discriminação racial relativos ao gênero. Revista Estudos Feministas, Florianópolis, v. 10, n. 1, p. 171, jan. 2002. Disponível em: https://periodicos.ufsc.br/index.php/ref/article/view/

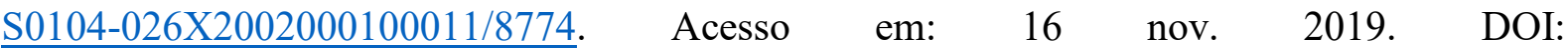
https://doi.org/10.1590/S0104-026X2002000100011.

FONSECA, Ingradi Iramaia Alves; CARDOSO, Fernando da Silva. Ciberativismo, empoderamento feminino e novas dinâmicas de enfrentamento à violência de gênero contra à mulher. Redes: R. Eletr. Dir. Soc., Canoas, v. 6, n. 1, mai., p. 133-156, 2018. Disponível em: 
https://revistas.unilasalle.edu.br/index.php/redes/article/view/4256/pdf. Acesso em: 15 nov. 2019. DOI: http://dx.doi.org/10.18316/redes.v6i1.4256.

FOUCAULT, Michel. Vigiar e punir: nascimento da prisão. Tradução de Raquel Ramalhete. 37. ed. Petrópolis RJ: vozes, 2009.

GOMES, Luiz Flávio. Lei de drogas comentada artigo por artigo: lei 11.343/2006, de 23.08.2006. 2. ed. rev., atual e ampl., São Paulo: Revista dos Tribunais, 2007.

GONZAGA, Maria Simone; CARDOSO, Fernando da Silva. Maternidade, cárcere e vivência de direitos reprodutivos na Colônia Penal Feminina de Buíque/PE. Revista de Estudos Empíricos em Direito / Brazilian Journal of Empirical Legal Studies. v. 5, n. 1, mar., 2018, p. 79-95. Disponível em: https://reedrevista.org/reed/article/view/304. Acesso em: 14 nov. 2019. DOI: https://doi.org/10.19092/reed.v5i1.304.

JAPIASSU, Carlos Eduardo Adriano. Tráfico de drogas e Constituição: um estudo jurídicosocial do tipo do art. 33 da Lei de Drogas diante dos princípios constitucionais-penais. Rio de Janeiro, 2009.

MIGUEL, Luis Felipe; BIROLI, Flávia. Feminismo e política: uma introdução. São Paulo: Boitempo, 2014.

RAMOS, Luciana de Souza. Por amor ou pela dor? Um olhar feminista sobre o encarceramento de mulheres por tráfico de drogas. 2012. 126 f. Dissertação (Mestrado em Direito), Programa de Pós-graduação em Direito, Faculdade de Direito da Universidade de Brasília, 2014.

SAFFIOTI, Heleieth Iara Bongiovani. Gênero, patriarcado, violência. São Paulo: Fundação Perseu Abramo, 2004.

SHECARIA, Sérgio Salomão (Org.). Drogas: uma nova perspectiva. São Paulo: IBCCrim, 2014. SCOTT, Joan Wallach. Gênero: uma categoria útil de análise histórica. Educação \& Realidade. Porto Alegre, v. 20, n. 2, p. 71-99, jul./dez., 1995. Disponível em: https://seer.ufrgs.br/educacaoerealidade/article/download/71721/40667. Acesso em: 14 nov. 2019. 
Revista

Debates Insubmissos

WOLA - Advocacy fo Human Rigths inthe American. Mulheres, políticas de drogas e encarceramento: um guia para a reforma em políticas na América Latina e no Caribe. Costa Rica: WOLA; Organização dos Estado Americanos, 2016.

Submetido em: 18/11/2019

Aprovado em: 27/12/2019 